\title{
Current Trends in Aesthetic Dentistry
}

\author{
Yousef A. AlJehani' ${ }^{1}$, Jagan K. Baskaradoss², Amrita Geevarghese ${ }^{3}$, Marey A. AlShehry ${ }^{3}$ \\ ${ }^{1}$ Dental Health Department, College of Applied Medical Sciences, King Saud University, Riyadh, KSA \\ ${ }^{2}$ Department of Dental Public Health, School of Dentistry, Case Western Reserve University, Cleveland, USA \\ ${ }^{3}$ College of Dentistry, King Saud Bin Abdulaziz University for Health Sciences, King Abdulaziz Medical City, \\ Riyadh, KSA \\ Email: aljehaniyousef@gmail.com
}

Received 7 June 2014; revised 22 July 2014; accepted 4 August 2014

Copyright (C) 2014 by authors and Scientific Research Publishing Inc.

This work is licensed under the Creative Commons Attribution International License (CC BY). http://creativecommons.org/licenses/by/4.0/

(c) (i) Open Access

\section{Abstract}

The level of aesthetic requirement in clinical practice has increased over the past decade, and this has made it necessary for dentist to explore this field in order to satisfy the existing demand in this field. Technology can provide a solution to many of the routine hassles in dental practice. While optimal systems are far from fully realized, technology undeniably has made enormous progress. This review aims to provide an update on some of the recent advances in the field of aesthetic dentistry. MEDLINE (1990 to Jan 2014), PubMed (using medical subject headings), and Google Scholar searched using the following terms "Dental Composites", "Ceramic Crowns", "Aesthetic Posts", "Ceramic Veneers", and "Computer-Aided Design/Computer Aided Manufacturing (CAD/CAM)". This was supplemented by hand-searching in peer-reviewed journals and cross-referenced with the articles accessed. Dentist and dental technician alike must be aware of the current technologies in their fields and be able to use it to their and their patient's advantage. The learning objective of this article is to review the advantages and disadvantages of recent esthetic materials and technology to aid in the proper utilization of the available treatment options with discretion.

\section{Keywords}

Ceramic Crowns, Aesthetic Posts, Ceramic Veneers, Computer-Aided Design/Computer Aided Manufacturing (CAD/CAM)

\section{Introduction}

Dental materials have special requirements. For health reasons, dental materials should be suitable for use in the oral environment. In certain applications, strength and durability of a dental material is important to ensure sa- 
tisfactory performance. In some other situations, the esthetic component would be more important.

Esthetic dental appearance of teeth is one of the patients' demands. This helped in the evolution of esthetic restorations, including the use of resin-based composite materials [1]-[7]. Restorative dentistry is a major specialty in practical clinical dentistry. In order to treat dental caries, we need to excavate the pathology and restore the cavity with a proper dental filling material. One of the options is the use of light polymerized direct-toothcolored restorative materials.

Resin-based composite restorative material is one of the light polymerized restorative materials, an accepted dental filling, and more clinically accepted from 1970s [8] [9]. Since then, evolution has made it one of the most commonly used types of filling; the light cured composite resin [2] [3] [9]. With its success rate is in an increasing scale [6] [9], composite restoration is being more and more used in restorative dentistry field.

Many countries have recognized the importance of technology assessment in dental care. Dental technology review is needed because of the rapid increase of published research and rising dental-care expenditures due to new dental treatment options. The pace of change with which dentists must cope daily in their practices has also accelerated. Evaluating, adopting, implementing new technologies, has taken an important role in a dental practice. Some of the areas which have emerged recently are Dental Composites, Aesthetic Posts, Ceramics, Veneers, Computer-aided design/Computer aided manufacturing (CAD/CAM). This paper looks at the advantages and disadvantages of each of these materials (Table 1).

Table 1. Advantages and disadvantages of the aesthetic materials.

\begin{tabular}{|c|c|}
\hline ADVANTAGES & DISADVANTAGES \\
\hline \multicolumn{2}{|l|}{ Dental Composites } \\
\hline Strong and durable & Tooth sensitivity \\
\hline Tooth colored & Technique sensitive \\
\hline Single visit for fillings & Costs more than dental amalgam \\
\hline Resists breaking & Shrinkage \\
\hline Maximum amount of tooth preserved & Leakage over time \\
\hline \multicolumn{2}{|l|}{ Does not corrode } \\
\hline \multicolumn{2}{|l|}{ Frequency of repair or replacement is low } \\
\hline \multicolumn{2}{|l|}{ Aesthetic Posts } \\
\hline Good retention without extensive tooth preparation & Restorative material's strength not increased \\
\hline Less time consuming & Induces stress \\
\hline Less expensive & Increased chances root canal perforation \\
\hline \multicolumn{2}{|l|}{ Ceramic Crowns } \\
\hline Esthetics & Expensive \\
\hline Low thermal conductivity & Technique sensitive \\
\hline No galvanic reactions & Post-operative pain from cementation \\
\hline Biocompatible & Excessive wear of opposing tooth \\
\hline \multicolumn{2}{|l|}{ CAD/CAM for Ceramic Restoration } \\
\hline Independence & Cost \\
\hline Reduced potential inaccuracies & Requirement of training \\
\hline \multicolumn{2}{|l|}{ Single appointment } \\
\hline \multicolumn{2}{|l|}{ Increased productivity } \\
\hline \multicolumn{2}{|l|}{ Ceramic Veneers } \\
\hline Esthetics & Brittle \\
\hline Stain resistant & Irreversible application process \\
\hline Durable & Cost \\
\hline Smooth, translucent surface provides a natural appearance & Tooth sensitivity \\
\hline
\end{tabular}




\section{Dental Composites (Figure 1)}

“Composite” refers to a mixture of different materials. Dental composites are tooth-colored filling materials composed of synthetic polymers, particulate ceramic reinforcing fillers, molecules which promote or modify the polymerization reaction that produces the cross-linked polymer matrix from the dimethacrylate resin monomers, and silane coupling agents which bond the reinforcing fillers to the polymer matrix [10]. Every component of the composite has a different function and contributes towards the success of the final dental restoration. However, the most significant developments in the evolution of commercial composites to date have been direct results of modifications to the filler component. Fillers are used in dental composites to provide strengthening [11], increased stiffness [12], reduced dimensional change when heated and cooled [13], reduced setting contraction [14], enhanced esthetics, and improved handling.

Ferracane [10] classified dental conposites based on the filler size as:

1) Microfills: Amorphous silica filler particles $(0.04 \mu \mathrm{m})$, pre-polymerized resin fillers (5 - $50 \mu \mathrm{m})$, inorganic filler volume $25 \%$ - 50\%;

2) Minifills: Barium, strontium or zirconia silicate fillers $(0.6-1.0 \mu \mathrm{m})$, amorphous silica $(0.04 \mu \mathrm{m})$, typical inorganic filler volume 50\% - 70\%;

3) Midfills: Barium, strontium or zirconia silicate fillers $(1-1.5 \mu \mathrm{m})$, amorphous silica $(0.04 \mu \mathrm{m})$, typical inorganic filler volume $55 \%$ - $70 \%$ and also contains quartz fillers.

\subsection{Advantages}

Dental composites are esthetic and relatively less expensive. The restoration can be completed in one day and it has also the property of "self-sealing". Another advantage is that these restorations can be easily repaired though the frequency of repair is relatively low.

\subsection{Disadvantages}

Sometimes after the placement of dental composites, the patient may complain of moderate tooth sensitivity. Another disadvantage is that the method of application is technique sensitive. It also costs more than dental amalgam. Dental composites tend to shrink when hardened and also may wear faster than dental enamel.

\section{Aesthetic Posts}

The introduction of aesthetic posts has made a great impact on the restoration of endodontically treated teeth. Since their introduction [15] [16], technology had modified and further improved post shape and materials; in

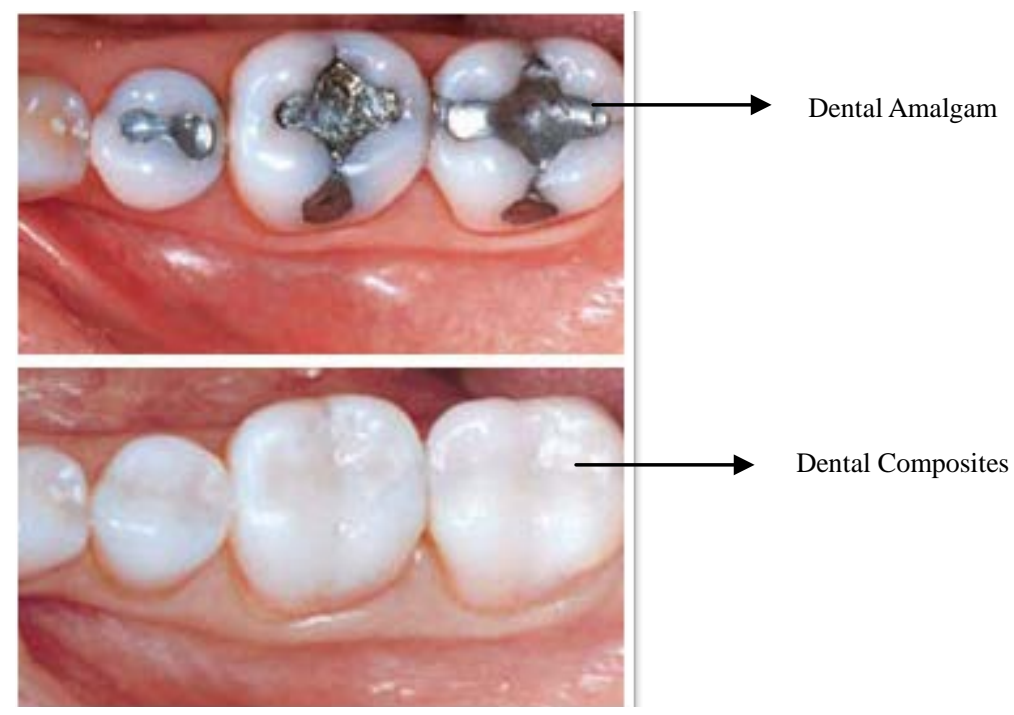

Figure 1. Dental composites. Courtesy: Durham dental fillings, Dr. Christopher Bouldin. 
addition, the use of innovative adhesive systems and cementation techniques has offered the possibility to achieve high level of adhesion within the root canal [17]-[19], producing new posts which ensure dental tissue conservation [19]. The restoration of endodontically treated teeth is a critical step in the success of root canal treatment [20]. Factors such as trauma and caries can lead to the creation of a large flared root canal. Traumatic impact on the anterior teeth in young patients often interrupts apical closure and full root development, leading to the formation of an enlarged root canal that remains flared. Flared canals are more susceptible to fracture because the remaining walls are thin, and the restoration of these teeth requires techniques that will not compromise the integrity of the remaining radicular tooth structure [21] [22]. Until 15 years ago, the restoration of these teeth involved a combination of prefabricated or custom made metallic posts and cores [22]. However, the introduction of materials that can bond to dentine has created an alternative option for the reconstruction and rehabilitation of root canals that have been severely damaged by caries, trauma, congenital disorders, or internal resorption [23]. Polyethylene fibers are used to improve the impact strength of composite materials, and they are nearly invisible in resinous matrices. For these reasons, polyethylene fibres seem to be the most appropriate and aesthetic strengtheners of composite materials [24] [25].

\subsection{Advantages}

The advantages of aesthetic posts are: It offers retention without the need for extensive preparation of tooth structure, it may increase resistance form of the tooth preparation to some extent, and it is less time consuming and less expensive than cast restorations which require multiple appointments [24].

\subsection{Disadvantages}

It does not increase the strength of the overlying restorative material. It induces stresses in dentin in the form of cracks or craze lines, which may increase the potential for the fracture of tooth and micro leakage. It could increase the chances of perforation into root canal or on the external tooth surface. The long term results are also not available [23].

\section{Ceramic Crowns (Figure 2)}

Ceramics are replacing metals as materials of choice in dental crowns [26], as well as in other biomechanical prostheses. Although alumina-based crowns continue to replace metal-based crowns, failure rates remain an issue [27]. Clinically, bulk fractures are the reported cause of all ceramic crown failure whether the crown is a monolith or a layered structure [28]. Failure generally does not result from damage at the occlusal surface, but rather from subsurface radial cracks at the cementation interface. The radial cracks are initially contained within the inner core layer, but subsequently propagate to the core boundaries, ultimately causing irretrievable failure.

\subsection{Advantages}

The major advantage of ceramic crowns is the esthetic result. The thermal conductivity is low for ceramics and
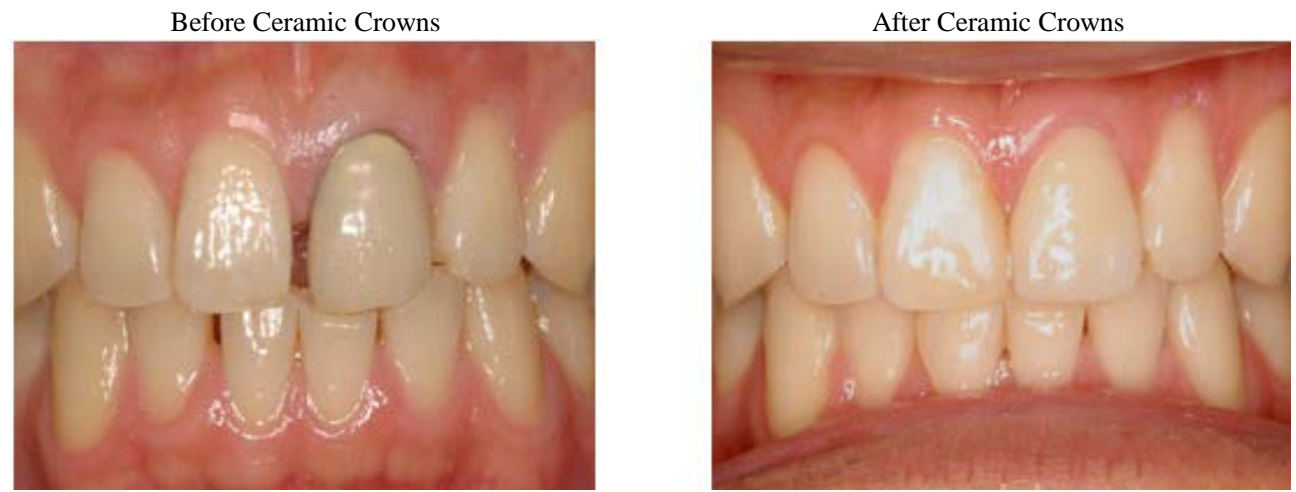

Figure 2. Ceramic crowns. Courtesy: Smile by design dental group, Dr. Choi. 
also it is resistant to corrosion. Also, there are no galvanic reactions for ceramics. Dental ceramics are claimed to be the most biocompatible materials used to date for dental restorations [29] [30].

\subsection{Disadvantages}

Ceramic crowns are expensive and require a high level of clinical skill. The process of preparation is technique sensitive and it requires the removal of considerable amount of sound tooth structure [31]. Occasional postoperative pain from cementation and bonding techniques has been reported. Excessive wear of opposing tooth may occur if ceramic surface is not properly glazed or polished [32].

\section{CAD/CAM for Ceramic Crowns (Figure 3)}

All-ceramic posterior crowns can be fabricated either as core crowns using CAD/CAM-generated copings, which are manually veneered by the laboratory technician or are CAD/CAM-generated as full monolithic crowns [33]. CAD/CAM (computer-aided design/computer aided manufacturing) systems have evolved over the last two decades and have been used by dental health professionals for over twenty years [34]. One of the main lines of implementation was the intraoperative use for dental restoration using prefabricated ceramic monoblocks [35]. The CAD/CAM systems have been used mostly for the manufacturing of prosthetic fixed restorations, such as inlays, onlays, veneers and crowns. Custom abutments created with CAD/CAM technology have the potential to provide the advantages of both stock and laboratory processed custom abutments without the disadvantages. First, like laboratory-made abutments, CAD/CAM abutments are specific for each patient [36], however the results are much more consistent. The virtually designed abutment is electronically transferred to a CAM milling apparatus that creates the abutment from a block of the selected abutment material. Most of the inherent dimensional inaccuracies of waxing, investing and casting are eliminated. Unlike stock or cast custom abutments, the abutment surfaces of CAD/CAM abutments are not subjected to the above-mentioned manipulation processes after machining, so CAD/CAM abutments have the potential to provide the most accurate fit of any abutment type. When compared with a stock and cast abutment, the cost of a CAD/CAM implant abutment presently lies somewhere between the two. This expense is likely to decrease over time as CAD/CAM systems for abutment fabrication become commonplace. Conversely, costs of manpower and labor-intensive laboratory processes are likely to escalate, thereby increasing the cost of prepared stock abutments or handmade cast custom abutments. Materials used CAD/CAM technology has used metals such as titanium and titanium alloys, and ceramics such as aluminum oxide or zirconium oxide for the fabrication of implant abutments [37].

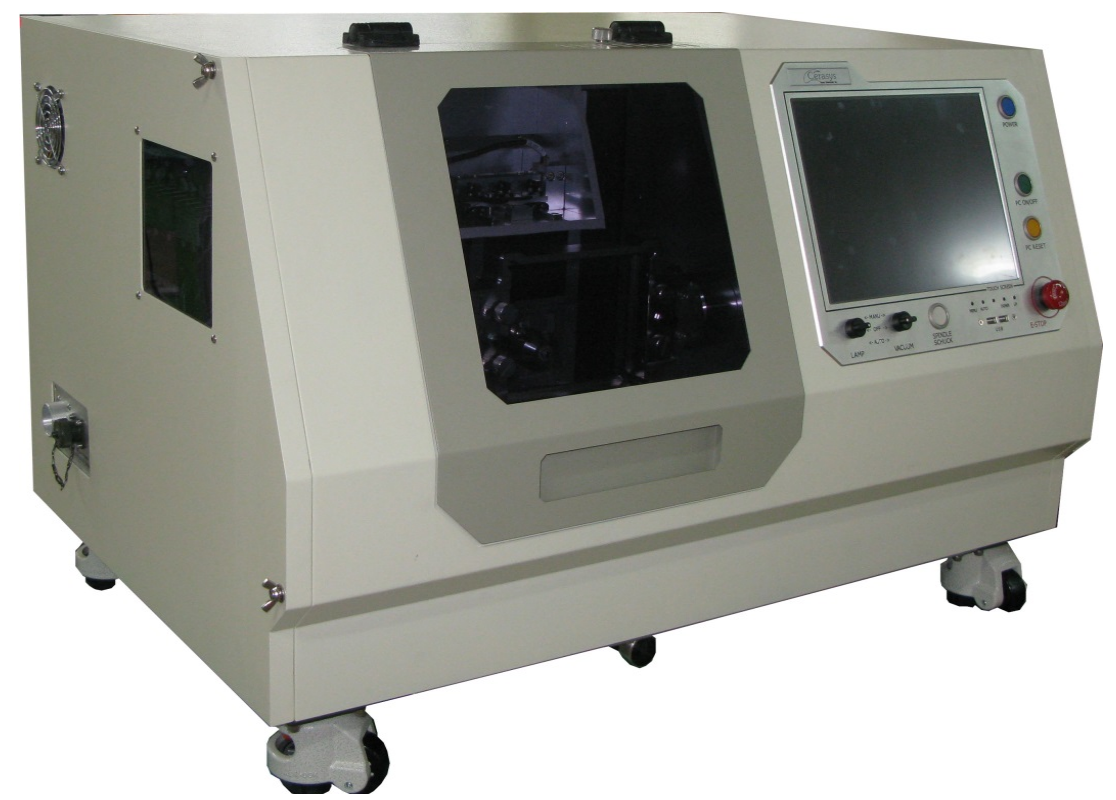

Figure 3. Dental CAD/CAM milling machine. Courtesy: Robots and design, Seongnam city, Gyunggi-do, Korea. 


\subsection{Advantages}

Many dentists enjoy and prefer having total control of their restorative services without involvement with a laboratory. In-office CAD/CAM restoration fabrication allows that independence. The computer and milling processes diminish potential inaccuracies resulting from the hand/laboratory fabrication process [38].

Dentists are able to delegate much of the CAD/CAM restoration fabrication procedure to competent, intelligent and motivated staff members, thereby freeing themselves to accomplish tasks that only they can legally perform. Patients appreciate the convenience of having restorations placed in one appointment, instead of having to come back for a second seating appointment. The in-office procedure is relatively fast, and because it enables the dentist to delegate much of the clinical procedure to staff members, the efficiency and productivity of the dental office can be improved. In-office CAD/CAM users report that they can perform more dental procedures, at a faster rate, with outcomes at least as predictable as and sometimes more predictable than those that resulted when they used conventional procedures.

\subsection{Disadvantages}

The cost of in-office CAD/CAM is a significant deterrent. Practitioners need to be convinced of its acceptability and practicability in their practices [39]. Becoming familiar with the CAD/CAM concept requires time and concentration, but after repeated use, the operation of the device becomes nearly automatic. As with any new technology, its cost is high, but using it can be financially feasible. Clinical and basic science investigations have resulted in positive findings on the concept.

\section{Ceramic Veneers (Figure 4)}

Since their introduction in the early 1980's ceramic veneers have gained wide acceptance as a primary mode of restoration in esthetic dentistry [40]. As patients' aesthetic expectations continue to increase, dental teams are challenged to identify a systematic approach for achieving natural oral and facial aesthetics with ceramic veneers. Advances in ceramic materials and veneering techniques allow practitioners to restore function and aesthetics using conservative and biologically sound methods as well as promoting long term oral health [41]. Aesthetics, treatment planning and clinical care should be considered in accordance with the interrelationship between the teeth, gingival tissues, lips and face. Consideration as to how the facial and psychological parameters can influence a natural smile design must also be taken into account. Because ceramic veneers are primarily indicated for the improvement of aesthetics, the design of the smile should respect the symmetry and the harmonious arrangement of dento-facial elements [42]. The patient is often the final judge of restorations in aesthetically driven treatment. If the clinician and patient do not have the same results in mind, there is the possibility that the patient will not approve the definitive restorations. For these reasons it is important to accurately visualize the restorations before finalization [43] [44].

\subsection{Advantages}

Some of the advantages of Porcelain veneers are: They are extremely natural looking. Porcelain and tooth enamel are both white and translucent. So they react to light in similar ways. Light enters them both and is reflected back off the layer beneath them. They are stain resistant and very durable [41].
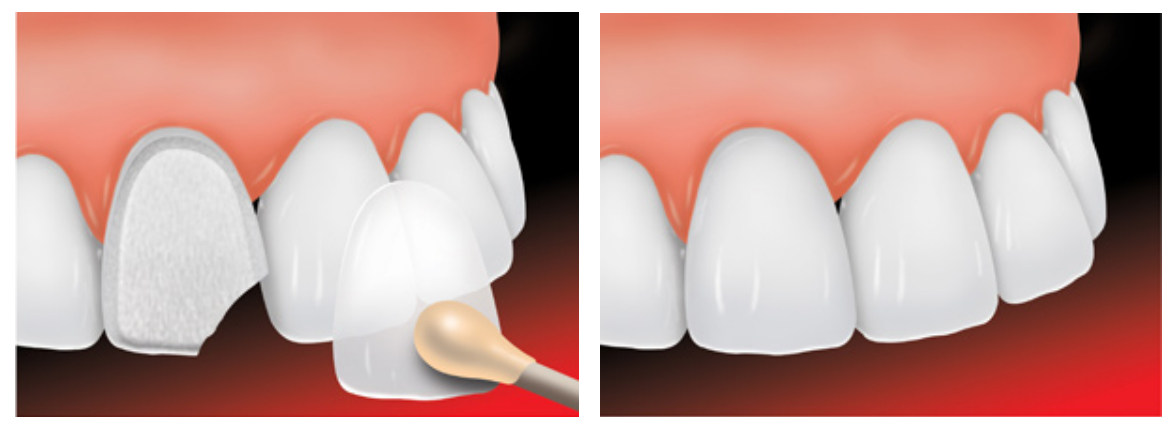

Figure 4. Ceramic veneers. Courtesy: Seasons of smiles dental, Dr. Norman Medina. 


\subsection{Disadvantages}

While porcelain veneers are an excellent choice for most people, there are some disadvantages that should be considered:

1) Porcelain veneers have a potential to break;

2) Porcelain veneer application is not a reversible process;

3) The porcelain veneer procedure is more expensive than composite dental veneers;

4) Increased tooth-sensitivity.

For most people, the benefits of porcelain veneer dental bonding far outweigh any negative aspects of the procedure.

\section{Conclusion}

Dentist and dental technician alike must be aware of the current technologies in their fields and be able to use it to their and their patient's advantage. The learning objective of this article is to review the advantages and disadvantages of recent esthetic materials and technology to aid in the proper utilization of the available treatment options with discretion.

\section{References}

[1] Burke, E.J. and Qualtrough, A.J. (1994) Aesthetic Inlays: Composite or Ceramic? British Dental Journal, 176, 53-60. http://dx.doi.org/10.1038/sj.bdj.4808363

[2] Mjor, I.A. (1997) Selection of Restorative Materials in General Dental Practice in Sweden. Acta Odontologica Scandinavica, 55, 53-57. http://dx.doi.org/10.3109/00016359709091942

[3] Hickel, R., et al. (1998) New Direct Restorative Materials. FDI Commission Project. International Dental Journal, 48, 3-16. http://dx.doi.org/10.1111/j.1875-595X.1998.tb00688.x

[4] Scheibenbogen-Fuchsbrunner, A., et al. (1999) Two-Year Clinical Evaluation of Direct and Indirect Composite Restorations in Posterior Teeth. Journal of Prosthetic Dentistry, 82, 391-397. http://dx.doi.org/10.1016/S0022-3913(99)70025-9

[5] Forss, H. and Widstrom, E. (2001) From Amalgam to Composite: Selection of Restorative Materials and Restoration Longevity in Finland. Acta Odontologica Scandinavica, 59, 57-62. http://dx.doi.org/10.1080/000163501750157090

[6] Ritter, A.V. (2001) Posterior Resin-Based Composite Restorations: Clinical Recommendations for Optimal Success. Journal of Esthetic and Restorative Dentistry, 13, 88-99. http://dx.doi.org/10.1111/j.1708-8240.2001.tb00431.x

[7] Roberts, H.W., et al. (2006) Accuracy of LED and Halogen Radiometers Using Different Light Sources. Journal of Esthetic and Restorative Dentistry, 18, 214-222. http://dx.doi.org/10.1111/j.1708-8240.2006.00023.x

[8] Pecina-Hrncevic, A. and Radovcic, J. (1982) Evaluation of the Success of Reconstructing Young Permanent Teeth with Composite Materials (Concise). Acta stomatologica Croatica, 16, 315-320.

[9] Manhart, J., et al. (2004) Buonocore Memorial Lecture. Review of the Clinical Survival of Direct and Indirect Restorations in Posterior Teeth of the Permanent Dentition. Operative Dentistry, 29, 481-508.

[10] Ferracane, J. (1995) Current Trends in Dental Composites. Critical Reviews in Oral Biology \& Medicine, 6, $302-318$. http://dx.doi.org/10.1177/10454411950060040301

[11] Chung, K.H. and Greener, E. (1990) Correlation between Degree of Conversion, Filler Concentration and Mechanical Properties of Posterior Composite Resins. Journal of Oral Rehabilitation, 17, 487-494. http://dx.doi.org/10.1111/j.1365-2842.1990.tb01419.x

[12] Kim, K.H., Park, J.H., Imai, Y. and Kishi, T. (1994) Microfracture Mechanisms of Dental Resin Composites Containing Spherically-Shaped Filler Particles. Journal of Dental Research, 73, 499-504.

[13] Yamaguchi, R., Powers, J.M. and Dennison, J.B. (1989) Thermal Expansion of Visible-Light-Cured Composite Resins. Operative Dentistry, 14, 64-67.

[14] Miyazaki, M., Hinoura, K., Onose, H. and Moore, B.K. (1991) Effect of Filler Content of Light-Cured Composites on Bond Strength to Bovine Dentine. Journal of Dentistry, 19, 301-303. http://dx.doi.org/10.1016/0300-5712(91)90078-D

[15] Asmussen, E., Peutzfeldt, A. and Heitmann, T. (1999) Stiffness, Elastic Limit, and Strength of Newer Types of Endodontic Posts. Journal of Dentistry, 27, 275-278. http://dx.doi.org/10.1016/S0300-5712(98)00066-9

[16] Drummond, J.L., Toepke, T.R. and King, T.J. (1999) Thermal and Cyclic Loading of Endodontic Posts. European Journal of Oral Sciences, 107, 220-224. http://dx.doi.org/10.1046/j.0909-8836.1999.eos1070310.x

[17] Ferrari, M., Vichi, A., Grandini, S. and Goracci, C. (2001) Efficacy of a Self-Curing Adhesive-Resin Cement System 
on Luting Glass-Fiber Posts into Root Canals: An SEM Investigation. The International Journal of Prosthodontics, 14, 543-549.

[18] Grandini, S., Goracci, C., Tay, F.R., Grandini, R. and Ferrari, M. (2005) Clinical Evaluation of the Use of Fiber Posts and Direct Resin Restorations for Endodontically Treated Teeth. The International Journal of Prosthodontics, 18, 399404.

[19] Carvalho, C.A., Valera, M.C., Oliveira, L.D. and Camargo, C.H.R. (2005) Structural Resistance in Immature Teeth Using Root Reinforcements in Vitro. Dental Traumatology, 21, 155-159. http://dx.doi.org/10.1111/j.1600-9657.2005.00312.x

[20] Belli, S., Erdemir, A. and Yildirim, C. (2006) Reinforcement Effect of Polyethylene Fibre in Root-Filled Teeth: Comparison of Two Restoration Techniques. International Endodontic Journal, 39, 136-142. http://dx.doi.org/10.1111/j.1365-2591.2006.01057.x

[21] Newman, M.P., Yaman, P., Dennison, J., Rafter, M. and Billy, E. (2003) Fracture Resistance of Endodontically Treated Teeth Restored with Composite Posts. Journal of Prosthetic Dentistry, 89, 360-367. http://dx.doi.org/10.1067/mpr.2003.75

[22] Sorensen, J.A. and Martinoff, J.T. (1984) Intracoronal Reinforcement and Coronal Coverage: A Study of Endodontically Treated Teeth. Journal of Prosthetic Dentistry, 51, 780-784. http://dx.doi.org/10.1016/0022-3913(84)90376-7

[23] Hornbrook, D.S. and Hastings, J.H. (1995) Use of Bondable Reinforcement Fiber for Post and Core Build-Up in an Endodontically Treated Tooth: Maximizing Strength and Aesthetics. Practical Periodontics: Aesthetic Dentistry, 7, 3342.

[24] Samadzadeh, A., Kugel, G., Hurley, E. and Aboushala, A. (1997) Fracture Strengths of Provisional Restorations Reinforced with Plasma-Treated Woven Polyethylene Fiber. Journal of Prosthetic Dentistry, 78, 447-450. http://dx.doi.org/10.1016/S0022-3913(97)70058-1

[25] Uzun, G., Hersek, N. and Tincer, T. (1999) Effect of Five Woven Fiber Reinforcements on the Impact and Transverse Strength of a Denture Base Resin. Journal of Prosthetic Dentistry, 81, 616-620. http://dx.doi.org/10.1016/S0022-3913(99)70218-0

[26] Kelly, J.R. (1999) Clinically Relevant Approach to Failure testing of All-Ceramic Restorations. Journal of Prosthetic Dentistry, 81, 652-661. http://dx.doi.org/10.1016/S0022-3913(99)70103-4

[27] Oden, A., Andersson, M., Krystek-Ondracek, I. and Magnusson, D. (1998) Five-Year Clinical Evaluation of Procera AllCeram Crowns. Journal of Prosthetic Dentistry, 80, 450-456. http://dx.doi.org/10.1016/S0022-3913(98)70010-1

[28] Thompson, J.Y., Anusavice, K.J., Naman, A. and Morris, H.F. (1994) Fracture Surface Characterization of Clinically Failed All-Ceramic Crowns. Journal of Dental Research, 73, 1824-1832.

[29] Bergman, M. (1990) Side-Effects of Amalgam and Its Alternatives: Local, Systemic and Environmental. International Dental Journal, 40, 4-10.

[30] Rykke, M. (1992) Dental Materials for Posterior Restorations. Dental Traumatology, 8, 139-148. http://dx.doi.org/10.1111/j.1600-9657.1992.tb00233.x

[31] Isidor, F. and Brondum, K. (1995) A Clinical Evaluation of Porcelain Inlays. Journal of Prosthetic Dentistry, 74, 140144. http://dx.doi.org/10.1016/S0022-3913(05)80176-3

[32] Jacobsen, P.H. and Rees, J.S. (1992) Luting Agents for Ceramic and Polymeric Inlays and Onlays. International Dental Journal, 42, 145-149.

[33] Bindl, A. and Mormann, W.H. (2002) An up to 5-Year Clinical Evaluation of Posterior In-Ceram CAD/CAM Core Crowns. International Journal of Prosthodontics, 15, 451-456.

[34] Duret, F., Blouin, J.L. and Duret, B. (1988) CAD-CAM in Dentistry. Journal of the American Dental Association, 117, 715-720.

[35] Mormann, W.H. (2004) The Origin of the Cerec Method: A Personal Review of the First 5 Years. International Journal of Computerized Dentistry, 7, 11-24.

[36] Petrungaro, P.S. (2003) Immediate One-Stage Implant Placement and CAD/CAM Abutments for Posterior Restorations. Practical Procedures Aesthetic Dentistry, 15, 595-599.

[37] Sherry, J.S., Sims, L.O. and Balshi, S.F. (2007) A Simple Technique for Immediate Placement of Definitive Engaging Custom Abutments Using Computerized Tomography and Flapless Guided Surgery. Quintessence International, 38, 755-762.

[38] Estafan, D., Dussetschleger, F., Agosta, C. and Reich, S. (2003) Scanning Electron Microscope Evaluation of CEREC II and CEREC III Inlays. General Dentistry, 51, 450-454.

[39] Rekow, E.D. (1993) High-Technology Innovations, and Limitations for Restorative Dentistry. Dental Clinics of North America, 37, 513-524. 
[40] Peumans, M., Van Meerbeek, B., Lambrechts, P. and Vanherle, G. (2000) Porcelain Veneers: A Review of the Literature. Journal of Dentistry, 28, 163-177. http://dx.doi.org/10.1016/S0300-5712(99)00066-4

[41] Malcmacher, L. (2003) Back to the Future with Porcelain Veneers. Dentistry Today, 22, 70-72.

[42] Bichacho, N. (1995) Porcelain Laminates: Integrated Concepts in Treating Diverse Aesthetic Defects. Practical Periodontics: Aesthetic Dentistry, 7, 13-23.

[43] Mizrahi, B. (2005) Visualization before Finalization: A Predictable Procedure for Porcelain Laminate Veneers. Practical Periodontics: Aesthetic Dentistry, 17, 513-518.

[44] Derbabian, K., Marzola, R., Donovan, T.E., Cho, G.C. and Arcidiacono, A. (2000) The Science of Communicating the Art of Esthetic Dentistry. Part II: Diagnostic Provisional Restorations. Journal of Esthetic and Restorative Dentistry, 12, 238-247. http://dx.doi.org/10.1111/j.1708-8240.2000.tb00230.x 
Scientific Research Publishing (SCIRP) is one of the largest Open Access journal publishers. It is currently publishing more than 200 open access, online, peer-reviewed journals covering a wide range of academic disciplines. SCIRP serves the worldwide academic communities and contributes to the progress and application of science with its publication.

Other selected journals from SCIRP are listed as below. Submit your manuscript to us via either submit@scirp.org or Online Submission Portal.
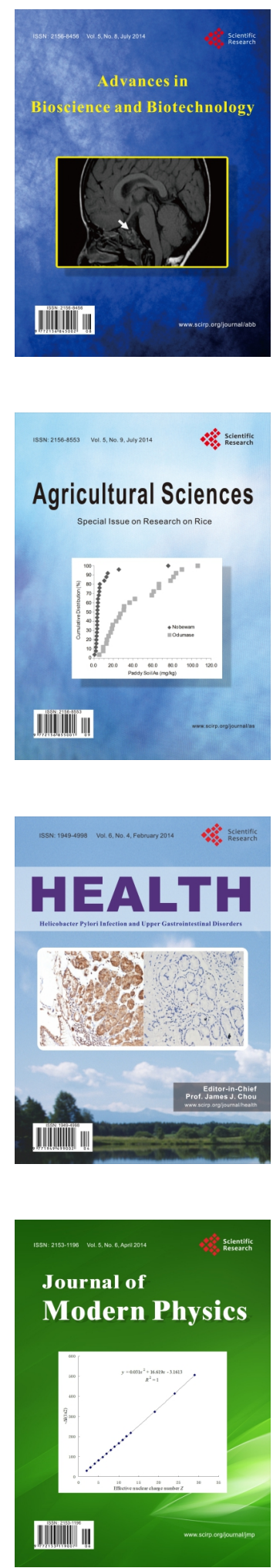
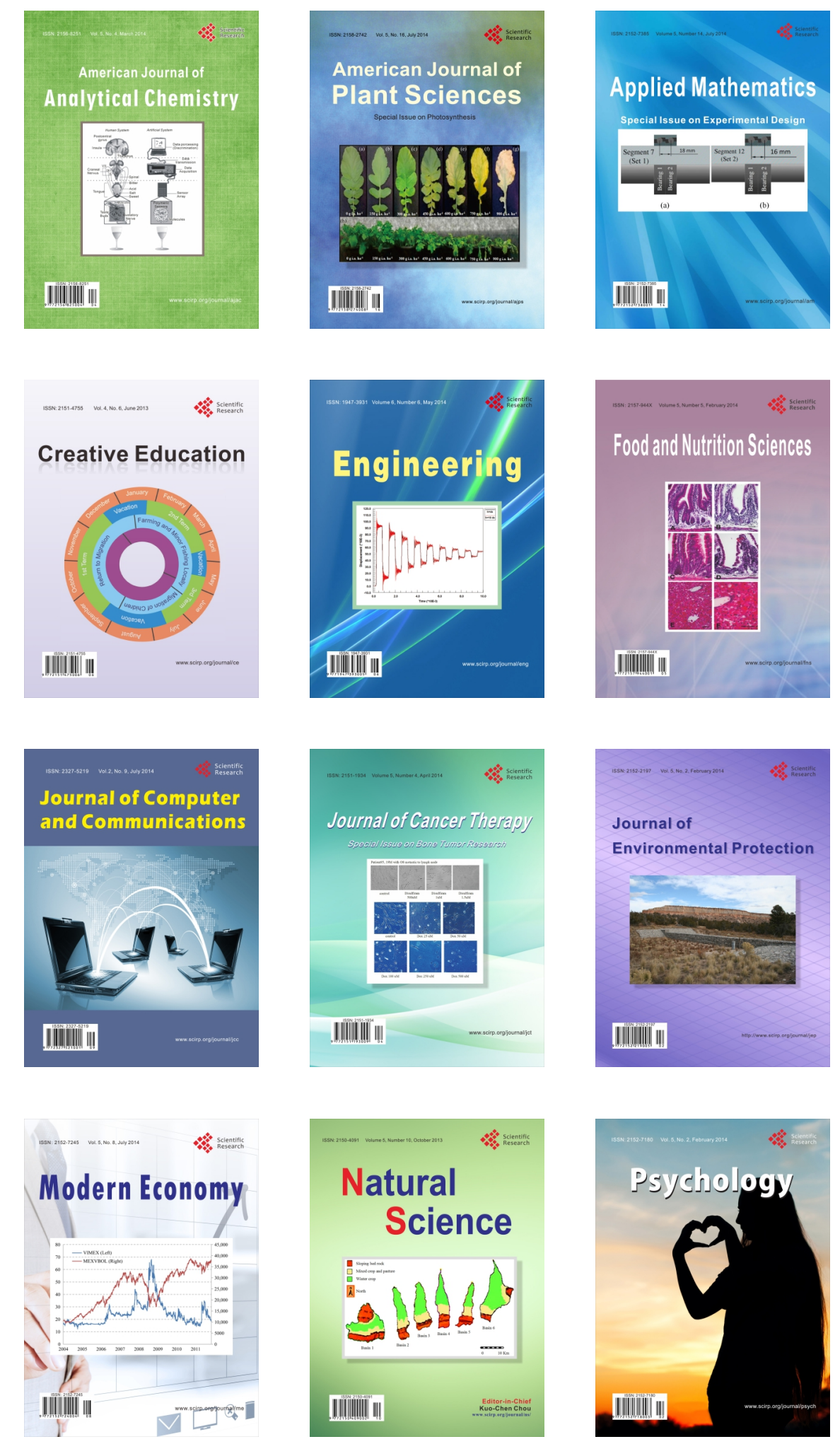